\title{
Resposta humoral ao vírus dengue em mães/filhos: relação com a sequência de Möbius
}

\author{
Humoral immune response to dengue virus in mothers/children: \\ relation with Möbius sequence
}

\author{
Diego Nery Benevides Gadelha ${ }^{1}$ \\ Bruna Vieira Ventura ${ }^{2}$ \\ Liana Maria Vieira de Oliveira Ventura ${ }^{3}$ \\ Marilyn T. Miller ${ }^{4}$ \\ Marli Tenório Cordeiro 5 \\ Célia Maria Machado Barbosa de Castro ${ }^{6}$
}

\begin{tabular}{l} 
RESUMO \\
\hline Objetivo: Investigar a resposta humoral para o vírus dengue em pacien- \\
tes com sequência de Möbius e suas mães, analisando a relação entre a \\
infecção na gestação e o nascimento de portadores da sequência de \\
Möbius. Métodos: Foram revisados os prontuários dos pacientes aten- \\
didos em centro de referência. Aplicou-se um questionário estruturado \\
a cada genitora. Sorologia por Elisa para IgG de dengue foi efetuada em \\
35 pacientes e suas mães. O teste de neutralização por redução em placas \\
foi feito nas que referiram infecção viral na gestação e em seus filhos, para \\
determinar o sorotipo viral causador da infecção. Resultados: Febre, \\
cefaléia e/ou dor retro-orbitária foi referida por 18 (51,4\%) mães. Três \\
(8,6\%) referiram dengue no primeiro ou início do segundo trimestre de \\
gestação. Cruzando-se as informações das sorologias das mães e crian- \\
ças observou-se que em 57,1\% dos casos há positividade sorológica para \\
o vírus do dengue na mãe e no filho. Das três mães com infecção na \\
gestação, uma e seu filho, apresentou teste de neutralização por redução \\
em placa positivo para o vírus dengue tipo três (DENV-3), entretanto o \\
sorotipo apenas foi introduzido em Pernambuco em 2002, o que exclui a \\
possibilidade de ter ocorrido transmissão vertical da doença. Conclusão: \\
As sorologias dos casos que tiveram diagnóstico clínico de dengue na \\
gravidez revelaram-se incompatíveis com a hipótese de ter ocorrido \\
transmissão vertical da doença. Portanto, na amostra estudada, a infec- \\
ção pelo vírus do dengue não pode ser considerada como fator implicado \\
na gênese da sequência de Möbius.
\end{tabular}

Descritores: Síndrome de Möbius/etiologia; Formação de anticorpos; Dengue; Dengue vírus

\section{INTRODUÇÃO}

Trabalho realizado na Fundação Altino Ventura - FAV
- Recife (PE) - Brasil.
${ }^{1}$ Médico, aluno do primeiro ano do Curso de Especiali-
zação em Oftalmologia da Fundação Altino Ventura -
FAV - Recife (PE) - Brasil.
${ }^{2}$ Acadêmica do quinto ano de Medicina da Universida-
de de Pernambuco - Recife (PE) - Brasil.
${ }^{3}$ Doutora em Oftalmologia pela Universidade Federal de
Minas Gerais - UFMG - Belo Horizonte (MG) - Brasil.
Coordenadora do Curso de Especialização em Oftalmo-
logia da FAV - Recife (PE) - Brasil. Coordenadora do
Departamento de Oftalmologia Pediátrica e Estrabismo
do Hospital de Olhos de Pernambuco - HOPE - Recife
(PE) - Brasil.
${ }^{4}$ Coordenadora e Professora do Departamento de Oftal-
mologia e Ciências Visuais da Universidade de Illinois
- Chicago - USA.
${ }^{5}$ Pesquisadora do Departamento de Virologia e Terapia
Experimental do Centro de Pesquisas Aggeu Magalhães
- Fiocruz - Recife (PE) - Brasil. Especialista em Virologia
e Mestre em Biotecnologia pela University of Kent - UK.
${ }^{6}$ Doutora pela Universidade Federal do Ceará - UFC -
Fortaleza (CE) - Brasil. Professora do Departamento de
Medicina Tropical da Universidade Federal de Pernam-
buco - UFPE - Recife (PE) - Brasil. Presidente da Comis-
são de Controle de Infecção Hospitalar da FAV - Recife
(PE) - Brasil.
Endereço para correspondência: Fundação Altino
Ventura - FAV. Rua da Soledade, 170 - Boa Vista -
Recife - PE - Brasil - CEP 50070-040.
E-mail: fav @ fundacaoaltinoventura.org.br
Recebido para publicação em 30.05.2008
Última versão recebida em 02.03.2009
Aprovação em 04.03.2009
Dida

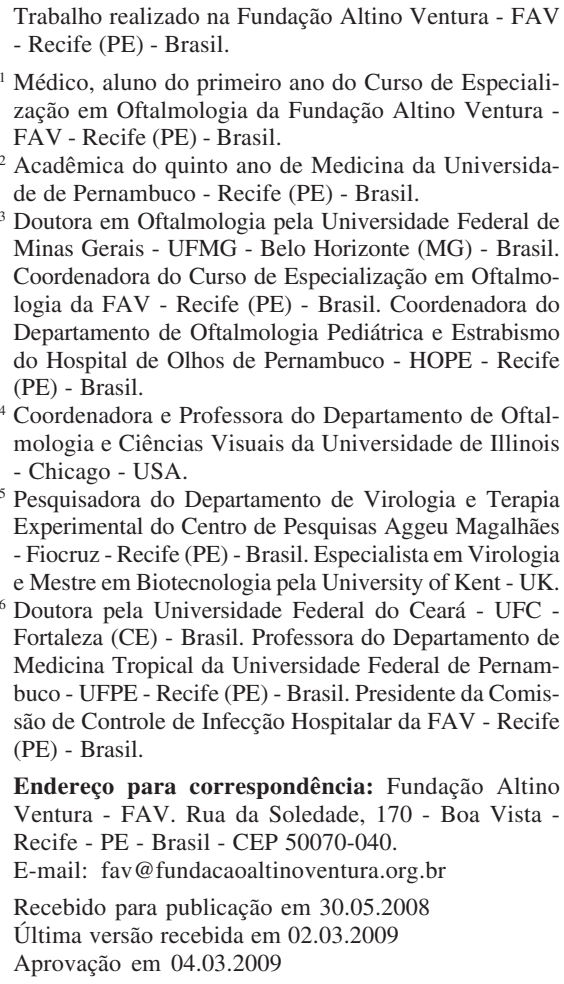

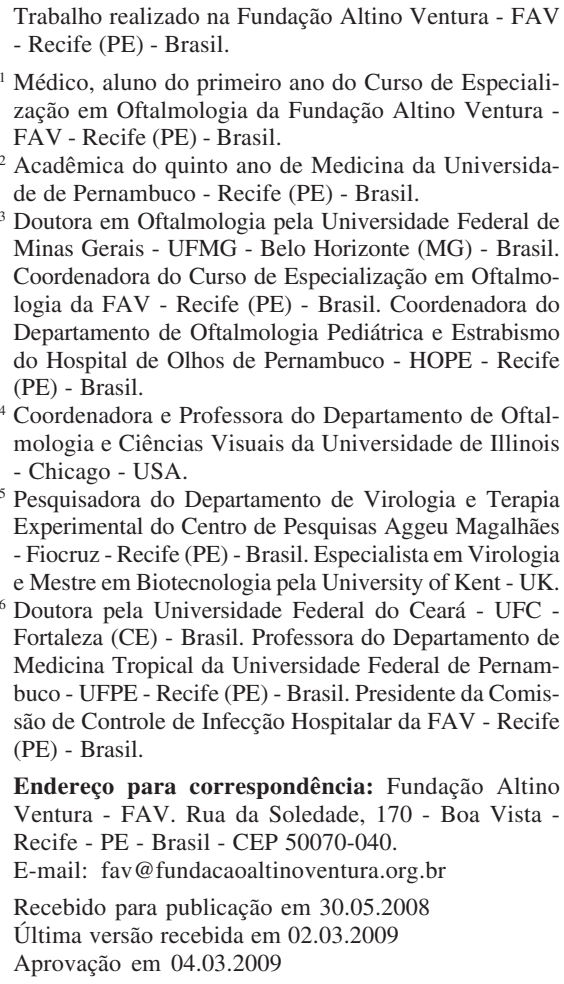

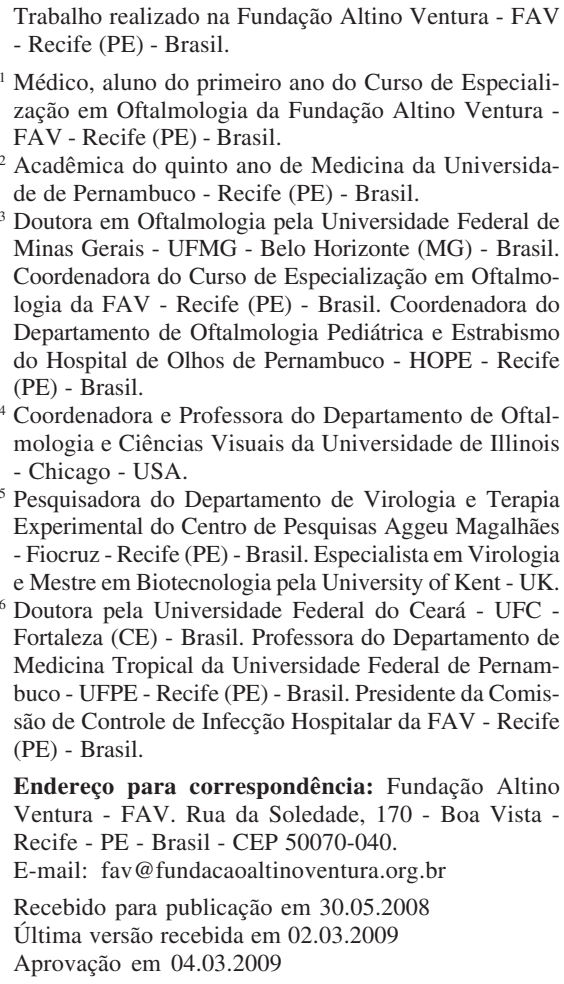

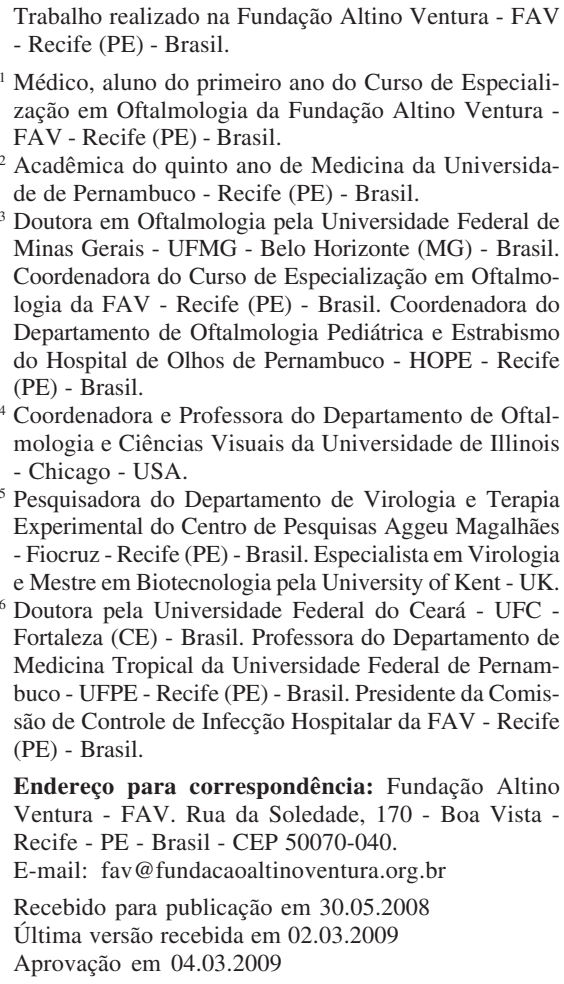

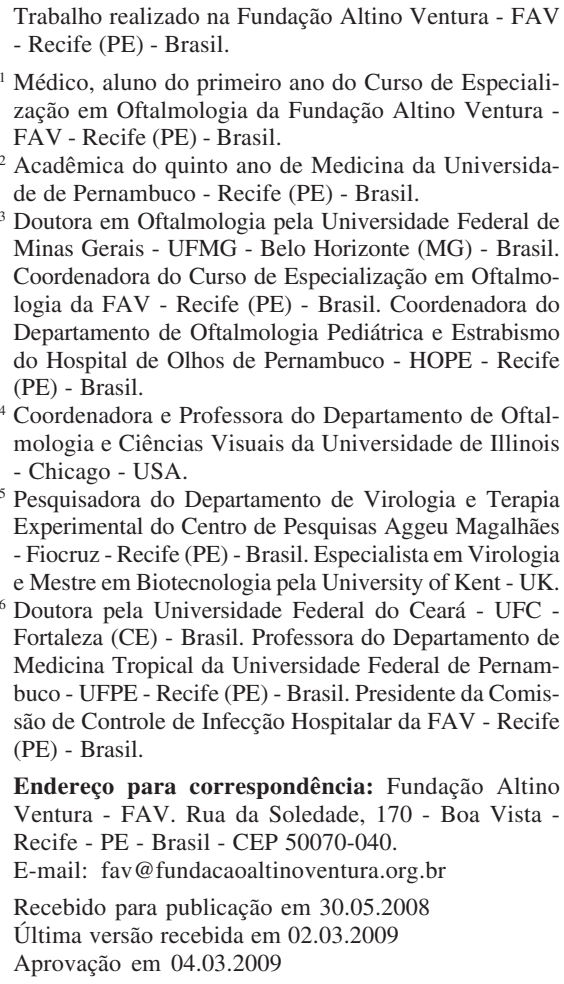

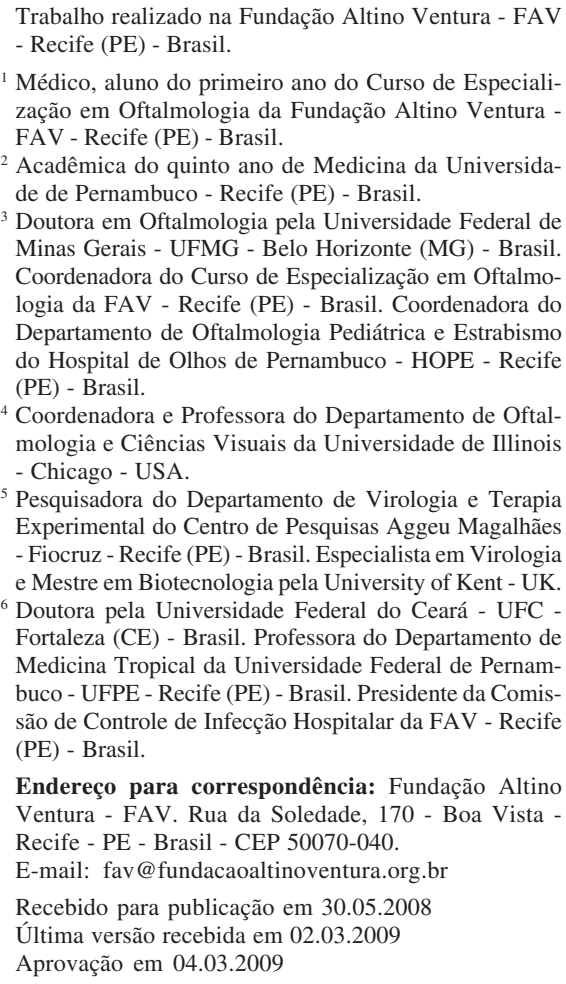

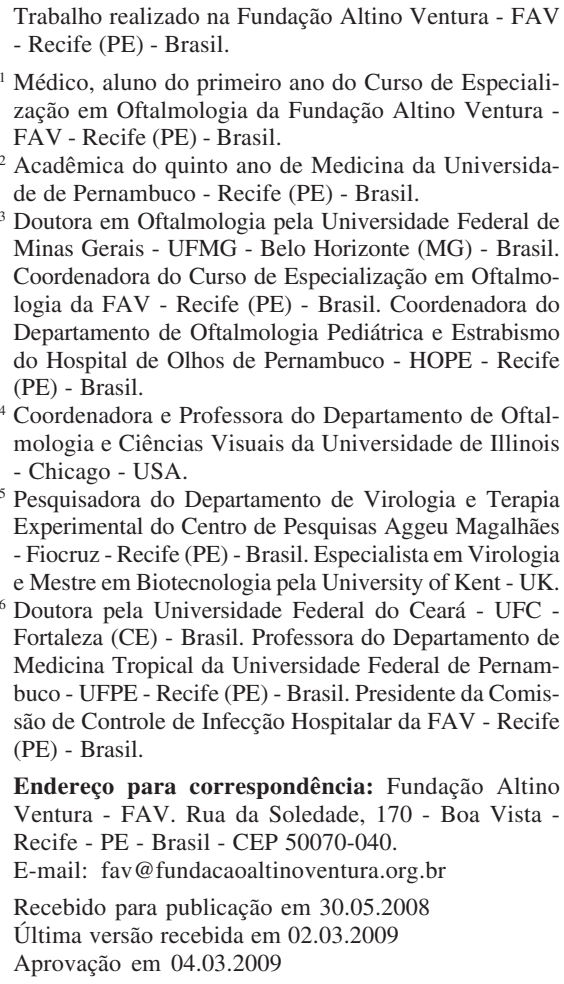

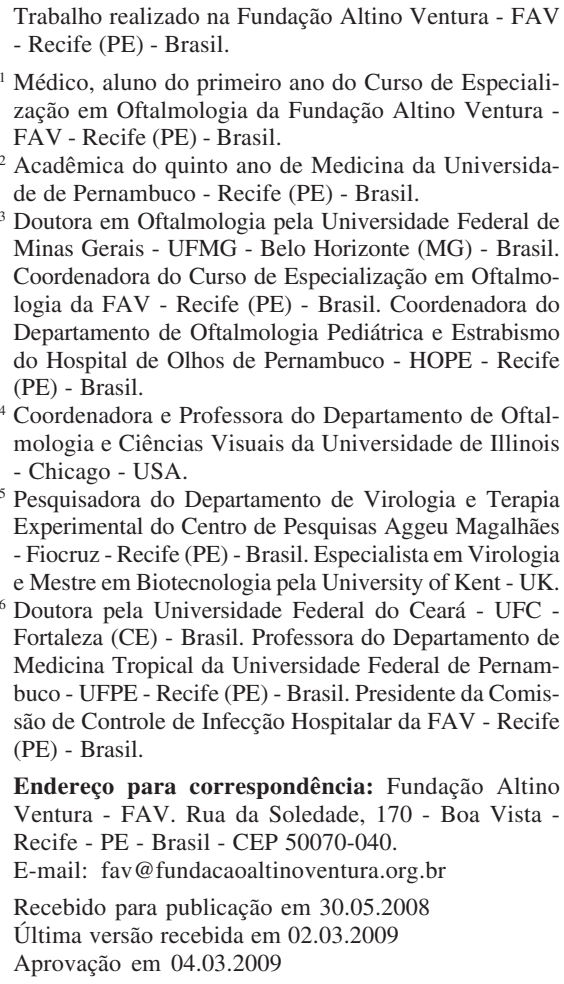

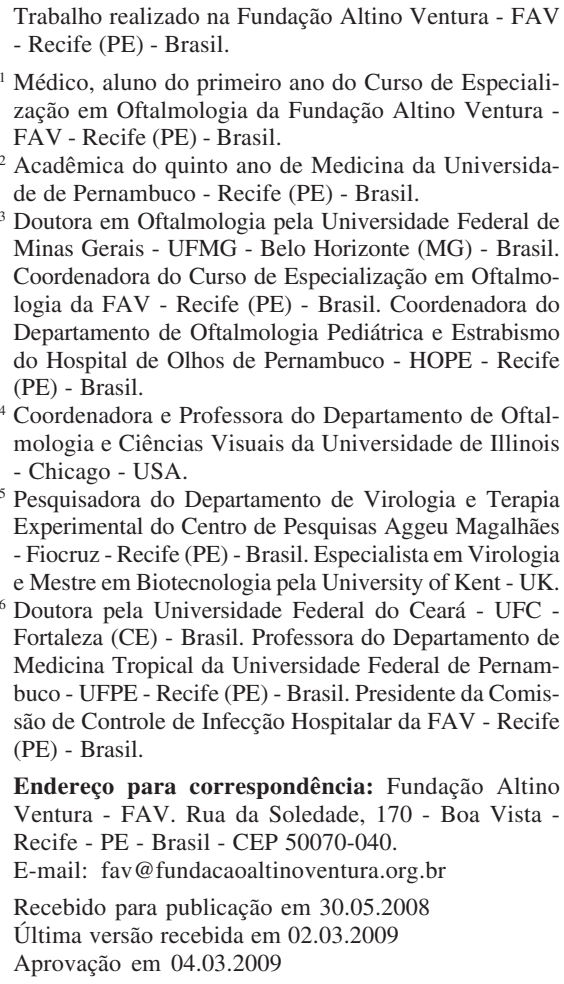

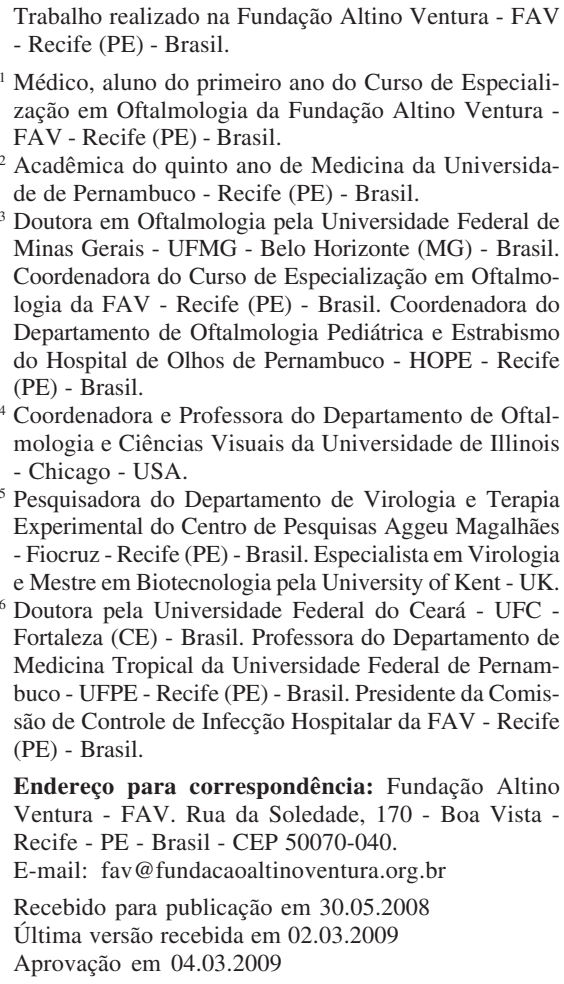

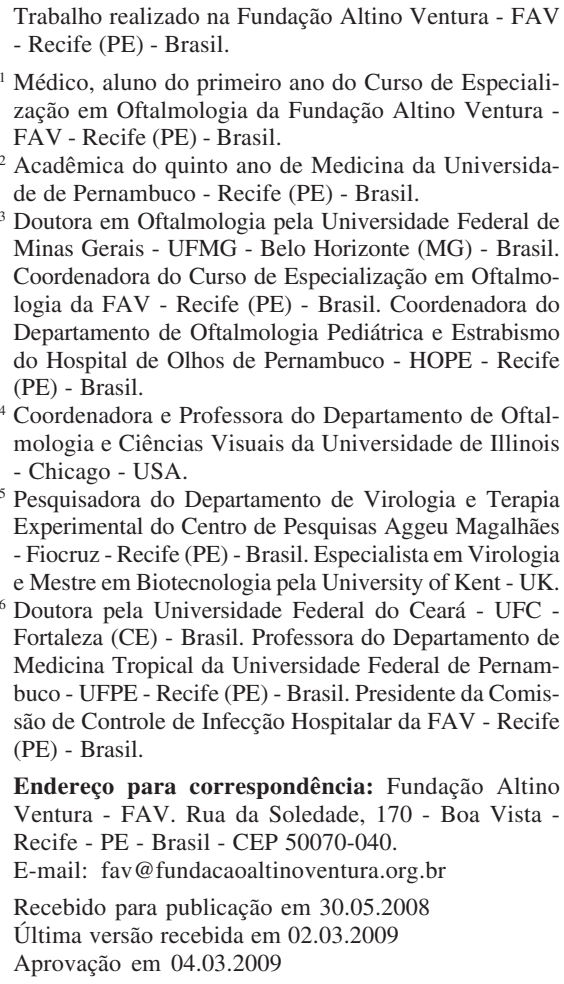

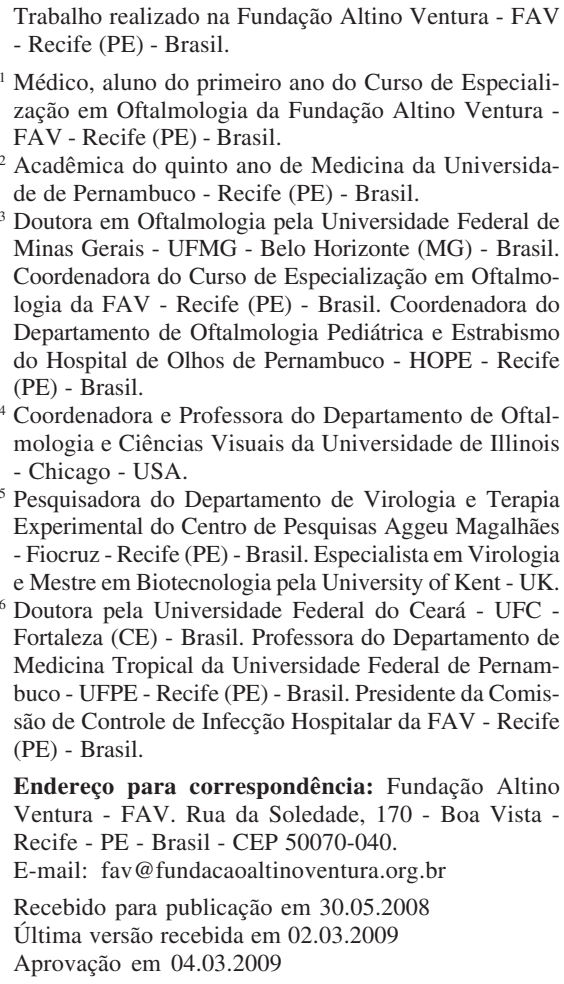

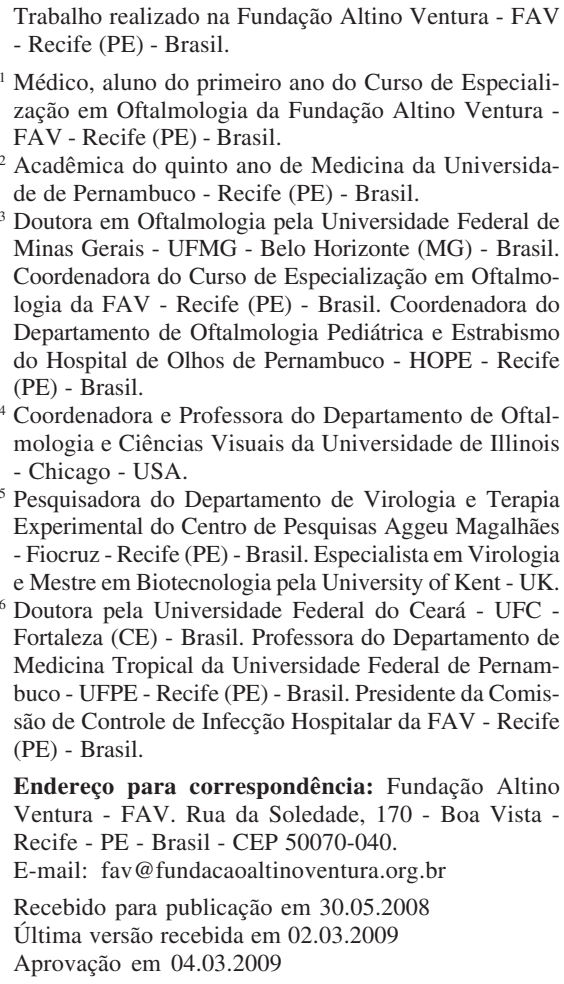

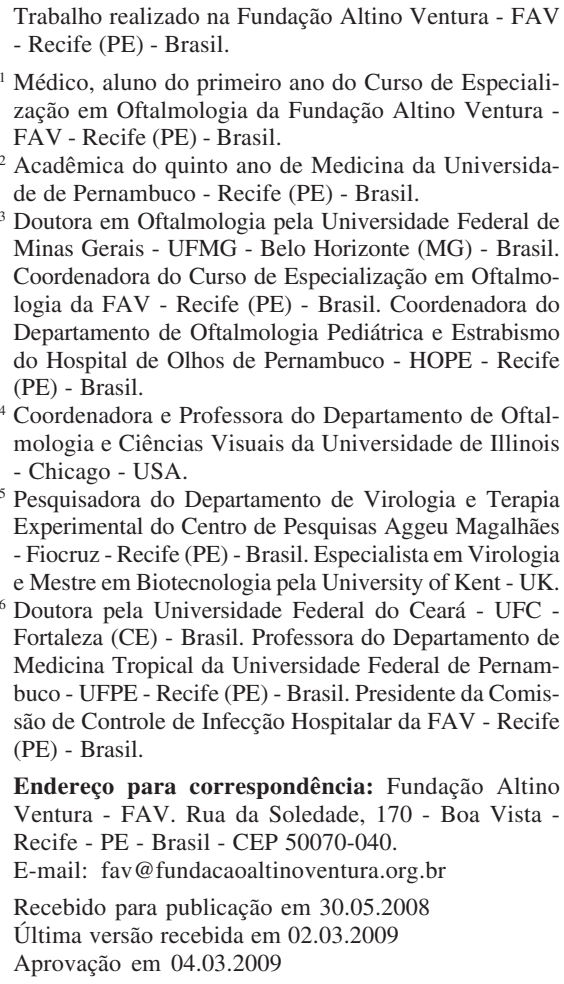

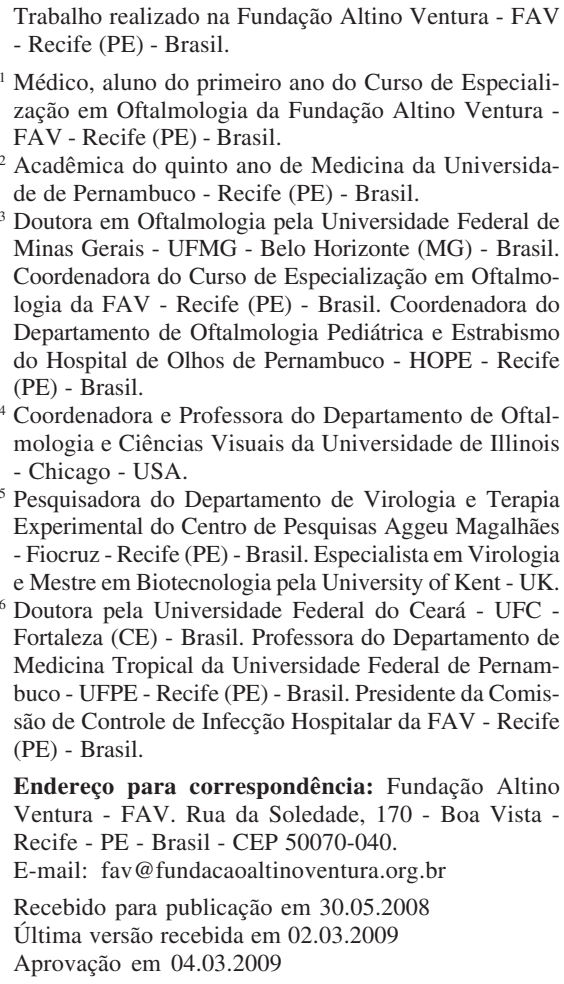

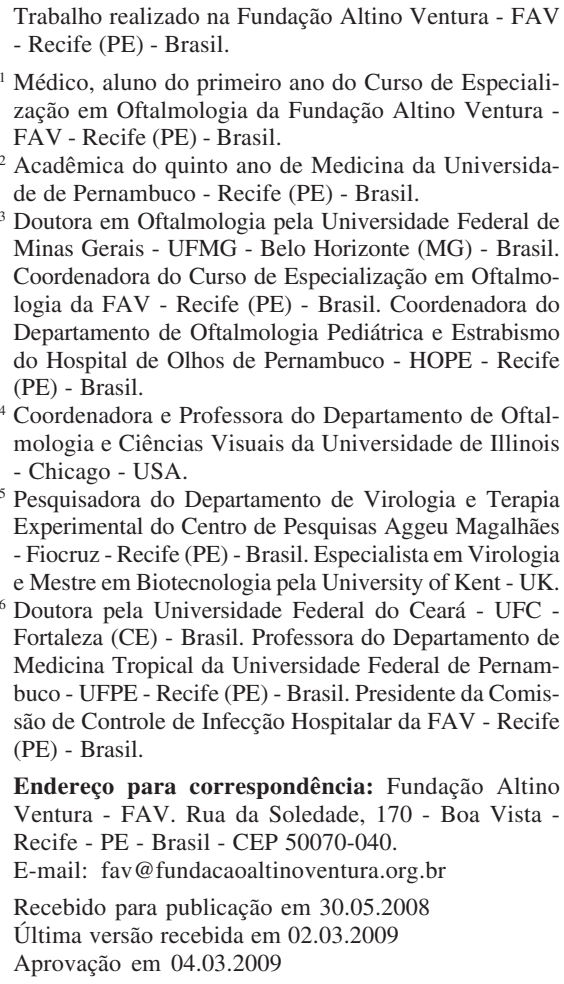

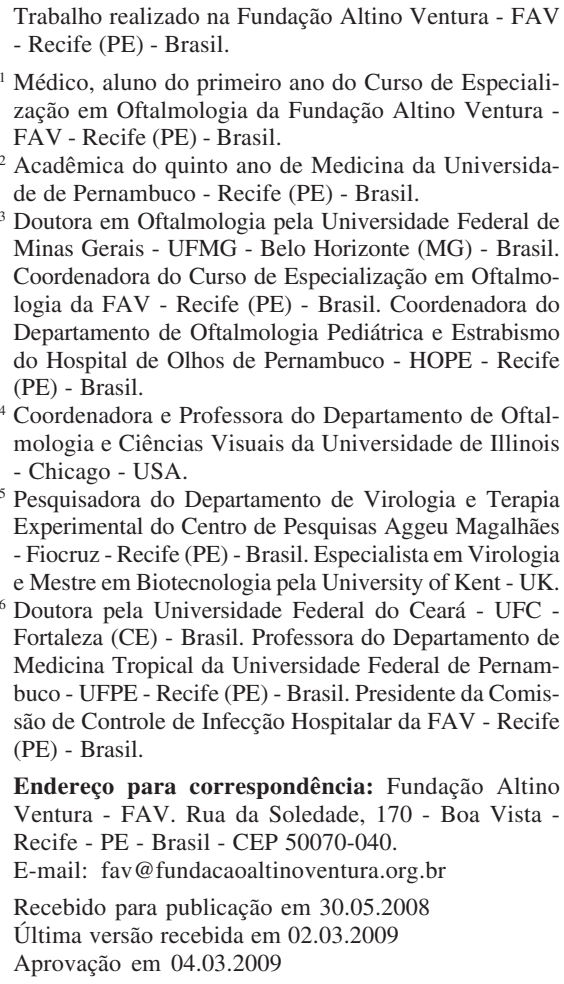

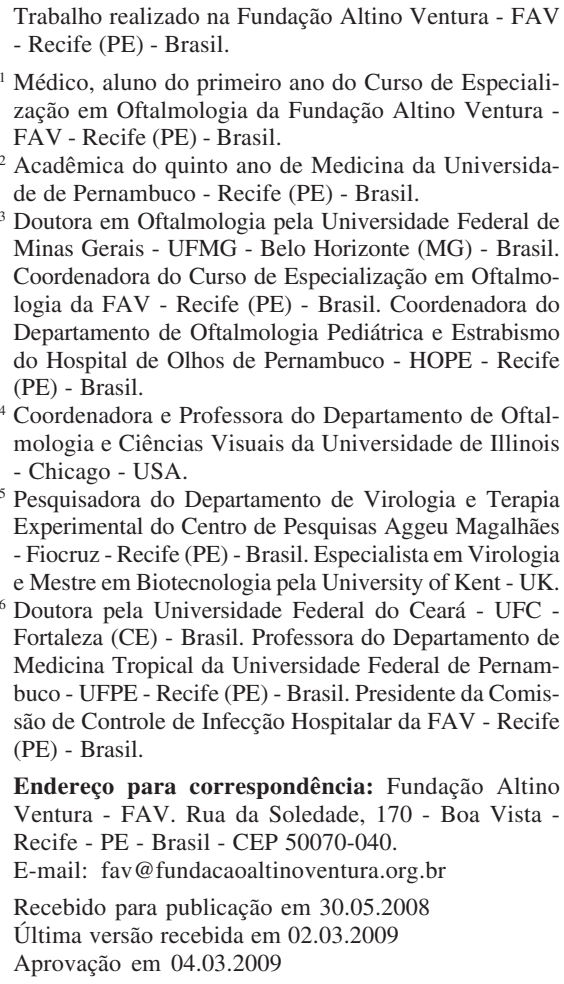

\section{INTRODU ÇA}

O mecanismo etiopatogênico mais aceito para explicar a sequência de Möbius é a hipótese de Bavinck e Weaver, que se baseia na ocorrência de uma insuficiência vascular no território das artérias subclávias, basilar, vertebral e torácica interna durante a morfogênese, no primeiro trimestre, possivelmente em torno da quarta e oitava semana de gestação ${ }^{(1-2)}$. Isto resultaria em uma alteração isquêmica do tronco cerebral, especialmente ao redor dos núcleos dos VI e VII nervos cranianos, provocando grande variedade de defeitos de derivados mesenquimais e ectodérmicos, a depender da localização específica da insuficiência vascular ${ }^{(2)}$. Adicionalmente, anormalidades de outros nervos cranianos e somatoesqueléticas ocorrem em diferentes proporções dependendo do estágio do desenvolvimento em que ocorreu a insuficiência vascular, e a gravidade e duração desta, produ- 
zindo padrões de Möbius com anomalias de diversas expressões fenotípicas ${ }^{(2-3)}$.

Acredita-se, atualmente, que a etiologia da sequência de Möbius seja multifatorial ${ }^{(4)}$. Existem alguns casos familiares e outros com mutações cariotípicas ${ }^{(5)}$. A maioria, entretanto, é de ocorrência esporádica ${ }^{(1,5-6)}$. Vários fatores ambientais têm sido implicados na gênese da sequência de Möbius, incluindo infecções, hipertermia, vasculite, coleta de vilosidade coriônica, trauma abdominal, falha na tentativa de aborto, uso de drogas tais como: misoprostol; talidomida; álcool ou cocaína ${ }^{(2,4-5)}$.

A gestante, fisiologicamente possui um estado de imunodepressão humoral e celular, portanto, mais susceptível ao aparecimento de infecções ${ }^{(7)}$. O processo inflamatório-infeccioso gerado por doenças infecciosas como dengue pode ocasionar alterações vasculares tais como aumento da permeabilidade, hemorragias, áreas de isquemia, vasculites e cho$q \mathrm{e}^{(8-11)}$. Estes fatores poderiam estar envolvidos no processo de insuficiência vascular presentes na gênese da sequência de Möbius.

O efeito da infecção por dengue em gestantes e nos seus fetos ainda é algo incerto, tendo sido sugerido em estudos anteriores, efeitos teratogênicos e resultados adversos variando desde casos leves até o abortamento ${ }^{(12-15)}$.

O presente estudo objetiva investigar a resposta humoral para a infecção pelo vírus dengue em pacientes com a sequência de Möbius e em suas mães, buscando avaliar possível relação entre a ocorrência desta infecção no período gestacional e o nascimento de pacientes com a sequência de Möbius.

\section{MÉTODOS}

Trata-se de um estudo descritivo, tipo série de casos, realizado na Fundação Altino Ventura, no período de julho de 2007 a março de 2008. Todos os 45 pacientes que possuem o diagnóstico de sequência de Möbius, que são acompanhados no Centro de Reabilitação Visual e/ou Múltiplas Deficiências da Fundação Altino Ventura "Menina dos Olhos", além de suas respectivas genitoras estavam aptos a participar do estudo. Todas as genitoras que concordaram em participar do estudo assinaram o Termo de Consentimento Livre e Esclarecido. Assinaram também o termo de responsabilidade por seus filhos.

Foram considerados para o diagnóstico de sequência de Möbius os seguintes critérios: presença de enfraquecimento congênito uni ou bilateral dos nervos abducente e facial, como achados isolados, ou quando associados ao acometimento de outros nervos cranianos, anomalias de extremidades, malformações craniofaciais, malformações musculoesqueléticas, retardo do desenvolvimento neuropsicomotor e autismo ${ }^{(1,4)}$.

Excluíram-se 10 pacientes e genitoras que não concordaram em participar do estudo ou que não compareceram para responder ao questionário. Participou do estudo um total de 70 indivíduos divididos em 35 pacientes e respectivas mães.
Os dados foram obtidos através de prontuários médicos e de um questionário estruturado fechado específico para o estudo que foi aplicado a cada genitora, envolvendo questões sobre as condições socioeconômicas da família, histórico de doenças no período gestacional, imunização prévia e uso de drogas no pré-natal.

Para o diagnóstico sorológico foi coletada de cada participante (filho e respectiva mãe) uma amostra de 5 a $10 \mathrm{ml}$ de sangue através de punção venosa, utilizando-se sistema de coleta a vácuo (Vacutainer, Becton Dickinson) em tubo seco para separação do soro. Após centrifugação do sangue, o soro foi separado e estocado a $-20^{\circ} \mathrm{C}$ para posterior realização dos testes sorológicos. Os testes sorológicos foram realizados no Departamento de Virologia do Centro de Pesquisas Aggeu Magalhães- Fiocruz.

Para a pesquisa dos anticorpos IgG para os vírus dengue (DENV) utilizou-se um kit comercial de ELISA em microplaca (PanBio, Pty Ltd., Brisbane, Austrália). Os resultados foram calculados e interpretados como positivo ou negativo de acordo com a recomendação do fabricante.

Das genitoras incluídas neste estudo, foram separadas aquelas que tinham história de diagnóstico de infecção por dengue no período gestacional. O soro destas mães e de seus respectivos filhos foi submetido ao teste de neutralização por redução em placas (PRNT), de acordo com o protocolo descrito por alguns autores ${ }^{(16)}$ para a quantificação dos anticorpos neutralizantes contra cada um dos três sorotipos DENV-1, DENV-2 e DENV-3. Os resultados foram expressos em títulos de anticorpos neutralizantes. A resposta humoral para o vírus dengue segue o seguinte critério: títulos $<1: 20$ indicam ausência de anticorpos para o vírus dengue, ou seja, indicativos de ausência de doença prévia por aquele sorotipo e títulos $>1: 20$ representam passado de infecção pelo sorotipo específico ${ }^{(16)}$.

O projeto foi aprovado no Comitê de Ética em Pesquisa da Fundação Altino Ventura.

\section{RESULTADOS}

Das 35 crianças incluídas no estudo, 19 (57,6\%) eram do sexo masculino e $16(45,7 \%)$ do feminino. A média de idade dos pacientes foi 9,5 $\pm 4,5$ anos, tendo o paciente mais novo cinco meses de vida e o mais velho 20 anos. A idade das mães variou de 22 a 49 anos, com média de 33,8 \pm 6,9 anos.

Quanto às condições econômicas, $32(91,4 \%)$ pacientes/ genitoras possuíam uma renda familiar mensal menor que três salários mínimos brasileiros, correspondente a U\$ 690.00, e apenas três $(8,6 \%)$ tinha renda mensal igual ou maior do que este valor.

Sintomas de febre, cefaléia ou dor retro-orbitária foi referido durante a gestação por $18(51,4 \%)$ das genitoras. O diagnóstico clínico de infecção pelo vírus do dengue foi referido por três mães $(8,6 \%)$, entre o primeiro e o segundo trimestre de gestação. História de rubéola na gestação foi referida por uma $(2,9 \%)$ genitora. (Gráfico 1). 
Quanto à sorologia, $21(60,0 \%)$ pacientes apresentaram IgG para o vírus do dengue, enquanto $30(85,7 \%)$ mães tinham sorologia positiva. Ao cruzar os dados, verificou-se que, 20 $(57,1 \%)$ genitoras e seus respectivos filhos apresentavam o teste de ELISA positivo.

Nas três genitoras com diagnóstico clínico de dengue na gravidez e em seus respectivos filhos, realizou-se o teste de neutralização para verificação do sorotipo viral. Constatou-se que em dois casos, a criança nunca apresentou infecção e no outro caso, o sorotipo causador da infecção tanto da mãe quanto da criança foi o DENV-3 (Tabela 1).

\section{DISCUSSÃO}

Dados gestacionais constituem valiosa fonte para pesquisa auxiliando na elucidação da etiologia dos casos de sequência de Möbius, no entendimento da embriopatia do neurodesenvolvimento. História familiar de eventos adversos na gravidez, principalmente devido a problemas socioeconômicos, frequentemente é relatada pelas genitoras dos pacientes com a sequencia de Möbius ${ }^{(17-20)}$.

As infecções encontram-se entre os vários fatores ambientais associados aos casos de sequência de Möbius. Alguns autores, descreveram um caso de sequência de Möbius, prematuro, cuja mãe tinha glomerulonefrite ${ }^{(18)}$. Outros autores, verificaram que em um dos casos estudados, havia história de resfriado $^{(19)}$. Em um estudo de 18 casos de Möbius, encontraram que durante o primeiro trimestre da gravidez duas mães tinham tido infecção viral inespecífica, uma havia relatado um "resfriado forte" e outra o diagnóstico não confirmado de rubéola ${ }^{(20)}$.

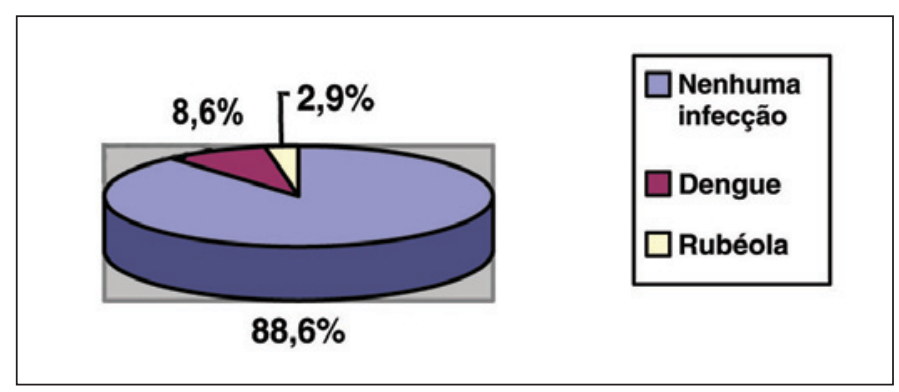

Gráfico 1 - Distribuição amostral segundo infecção no perído gestacional
Revisando-se todos os protocolos de pesquisas realizadas anteriormente pela Fundação Altino Ventura em pacientes com sequência de Möbius, verificou-se história clinica de infecção pelo vírus do dengue em três casos. Desenhou-se o presente estudo visando obter-se a resposta quanto à provável influencia desta infecção na gênese da sequência de Möbius.

No Brasil, o dengue é uma doença endêmica com picos epidêmicos ${ }^{(21)}$. No Estado de Pernambuco, de 1995 a 2006, 55\% de todos os casos da doença ocorreram em pessoas entre $20 \mathrm{e}$ 49 anos de idade, sendo as mulheres mais acometidas que os homens ${ }^{(22)}$. Todas as mães dos pacientes com sequência de Möbius incluídas no presente estudo apresentavam-se nesta faixa etária de risco e viviam neste Estado do país.

A maioria $(68,6 \%)$ dos pacientes/genitoras possuía renda familiar mensal menor que um salário mínimo brasileiro. Já foi evidenciado que áreas com nível socioeconômico mais baixo e com maior concentração populacional apresentam condições mais favoráveis à proliferação do vetor e, portanto, maior risco de transmissão de dengue ${ }^{(23-24)}$.

Em um estudo analisando 22 filhos de mães que tiveram dengue na gravidez, foram encontrados três casos de malformações congênitas ${ }^{(9)}$. Uma pesquisa realizada na Índia sugeriu que uma epidemia de dengue resultou em um aumento de três vezes na incidência de fetos com defeito do tubo neu$\mathrm{ral}^{(14)}$. Distintas investigações realizadas em mulheres que tiveram dengue no período gestacional evidenciaram que esta doença pode resultar até em óbito fetal ${ }^{(12-13,15)}$.

$\mathrm{O}$ dengue tem repercussões vasculares importantes, podendo ter formas oligo e assintomática ou até quadros com hemorragia e choque ${ }^{(21)}$. Sabendo-se que dentre as várias teorias que tentam explicar a fisiopatogenia na sequência de Möbius, a mais aceita é a que sugere existir um insuficiente aporte sangüíneo ao tronco cerebral nos primórdios da gravidez ${ }^{(2,11)}$. Alguns casos de Möbius, poderiam ser atribuídos ao processo isquêmico gerado na infecção pelo vírus do dengue. Este estudo foi planejado para tentar responder a esta pergunta. Entretanto apresentou como viés, o fato de que a sequência de Möbius é rara ${ }^{(17)}$. Sendo assim, existe dificuldade de realizar um estudo prospectivo e observacional com gestantes que apresentem sintomas de dengue, realizando a sorologia (IgM e $\operatorname{IgG}$ ) durante a gravidez e a dos filhos no pós-parto.

$\mathrm{Na}$ amostra estudada, verificou-se a presença de quase $90 \%$ das genitoras e pouco mais de $60 \%$ dos pacientes com

\begin{tabular}{|c|c|c|c|c|c|}
\hline \multirow[t]{2}{*}{ Número do caso } & \multirow[t]{2}{*}{ Idade em anos } & \multirow[t]{2}{*}{ IgG dengue } & \multicolumn{3}{|c|}{ Teste de neutralização - PRNT } \\
\hline & & & DENV-1 & DENV-2 & DENV-3 \\
\hline 1. Mãe & 37 & Positivo & $<1: 20(-)$ & $<1: 20(-)$ & $1: 160(+)$ \\
\hline 1. Filho & 20 & Positivo & $<1: 20(-)$ & $<1: 20(-)$ & $1: 80 \quad(+)$ \\
\hline $\begin{array}{l}\text { 2. Mãe } \\
\text { 2. Filho }\end{array}$ & $\begin{array}{r}43 \\
9\end{array}$ & $\begin{array}{l}\text { Positivo } \\
\text { Negativo }\end{array}$ & $\begin{array}{l}<1: 20(-) \\
<1: 20(-)\end{array}$ & $\begin{array}{l}<1: 20(-) \\
<1: 20(-)\end{array}$ & $\begin{array}{r}1: 160(+) \\
<1: 20 \quad(-)\end{array}$ \\
\hline 3. Mãe & 23 & Positivo & $<1: 20(-)$ & $<1: 20(-)$ & $1: 320(+)$ \\
\hline 3. Filho & 4 & Negativo & $<1: 20(-)$ & $<1: 20(-)$ & $<1: 20(-)$ \\
\hline
\end{tabular}


IgG para o vírus do dengue. Ao se juntar os dados de filhos/ mães, verificou-se que $57,1 \%$ das mães e seu respectivo filho apresentavam o teste ELISA positivo, indicando que ambos genitora e filho - tenham tido a infecção, durante algum período de suas vidas. Considerando-se que Pernambuco é um estado de média incidência de dengue, com 218,7 casos de dengue/100.000 habitantes em $2006^{(22)}$, estes pacientes podem ter sido infectados em momentos diferentes.

Nas três genitoras com diagnóstico clínico de dengue no primeiro e segundo trimestre da gestação e em seus respectivos filhos, o teste de neutralização revelou que em dois casos, a criança nunca apresentou infecção, tornando-se improvável que tenha havido transmissão vertical da infecção. No outro caso, com história negativa para uso do misoprostol, o sorotipo causador da infecção de dengue tanto da mãe quanto da criança foi o DENV-3. Como o paciente tem 20 anos e o DENV3 só começou a circular em Pernambuco em $2002^{(25)}$, a infecção vertical pode ser descartada.

\section{CONCLUSÃO}

Este é o primeiro estudo a realizar uma sorologia de pacientes com sequência de Möbius e suas genitoras buscando analisar a possível associação da infecção viral por dengue e a sequência de Möbius. Apesar de haver um espectro de formas oligo e assintomática no dengue que variam até formas bastante sintomáticas e graves, a sorologia dos casos que tiveram diagnóstico clínico de dengue na gravidez revelaram-se incompatíveis com a hipótese de ter ocorrido transmissão vertical da doença. Dessa forma, na amostra estudada, a infecção pelo vírus do dengue não pode ser considerada como fator implicado na gênese da sequência de Möbius.

\section{ABSTRACT}

Purpose: To investigate the humoral immune response to dengue virus in patients with Möbius sequence and their mothers, assessing the relation between this infection during pregnancy and Möbius sequence. Methods: The medical records were reviewed, and a questionnaire was answered by each mother. IgG ELISA was performed in 35 patients and their mothers. A plaque reduction neutralization test was further done in the mothers who reported a viral infection during pregnancy and in their children for determining which dengue serotype virus had caused the infection. Results: Fever, headache and/or retrobulbar pain during pregnancy was referred by eighteen $(51.4 \%)$ mothers. Three $(8.6 \%)$ reported dengue during the first or second quarteers of pregnancy. When cross analyzing the mothers and their respective children serological results, $57.1 \%$ of them matched. Of the three mothers with clinical diagnosis of viral infection during pregnancy, one and its respective children had a positive plaque reduction neutralization test for dengue serotype three (DENV-3), this serotype reached Pernambuco in 2002, which excludes the possibility of a vertical transmission to the children. Conclusion: The serology of the cases that had clinical diagnosis of dengue during pregnancy proved to be incompatible with the hypothesis of the disease vertical transmission. Therefore, in the present serie, the dengue virus infection can not be considered as a factor involved in the genesis of Möbius sequence.

Keywords: Möbius syndrome/etiology; Antibody formation; Dengue; Dengue virus

\section{REFERÊNCIAS}

1. Strömland K, Sjögreen L, Miller M, Gillberg C, Wentz E, Johansson M, et al. Möbius sequence: a Swedish multidiscipline study. Eur J Paediatr Neurol. 2002;6(1):35-45.

2. Bavinck JN, Weaver DD. Subclavian artery supply disruption sequence: hypothesis of a vascular etiology for Poland, Klippel-Feil, and Möbius anomalies. Am J Med Genet. 1986;23(4):903-18.

3. D'Cruz OF, Swisher CN, Jaradeh S, Tang T, Konkol RJ. Möbius syndrome: evidence for a vascular etiology. J Child Neurol. 1993;8(3):260-5.

4. Fontenelle L, Araújo AP, Fontana RS. Síndrome de Moebius: relato de caso. Arq Neuropsiquiatr. 2001;59(3-B):812-4.

5. Shashikiran ND, Subba Reddy VV, Patil R. "Moebius syndrome": a case report. J Indian Soc Pedod Prev Dent. 2004;22(3):96-9.

6. Kumar D. Moebius syndrome. J Med Genet. 1990;27(2):122-6.

7. Phupong V. Dengue fever in pregnancy: a case report. BMC Pregnancy Childbirth. 2001;1(1):7.

8. Miller E, Cradock-Watson JE, Pollock TM. Consequences of confirmed maternal rubella at successive stages of pregnancy. Lancet. 1982;2(8302):781-4.

9. Restrepo BN, Isaza DM, Salazar CL, Ramírez JL, Upegui GE, Ospina M, et al Neonatal and postnatal effects of dengue infection during pregnancy. Biomedica. 2003;23(4):416-23.

10. Henderson JL. The congenital facial diplegia syndrome: clinical features, pathology and ætiology: a review of sixty-one cases. Brain 1939;62:381-403.

11. Hinrichsen SL, Duarte LEM, Jucá M, Filho AFM. Rubéola. In: Hinrichsen SL. DIP doenças infecciosas e parasitárias. Rio de Janeiro: Guanabara Koogan; 2005. p.115-7.

12. Ismail NA, Kampan N, Mahdy ZA, Jamil MA, Razi ZR. Dengue in pregnancy. Southeast Asian J Trop Med Public Health. 2006;37(4):681-3. Comment in: Southeast Asian J Trop Med Public Health. 2007;38(1):195-6.

13. Carles G, Talarmin A, Peneau C, Bertsch M. [Dengue fever and pregnancy. A study of 38 cases in french Guiana]. J Gynecol Obstet Biol Reprod (Paris). 2000; 29(8):758-62. French.

14. Sharma JB, Gulati N. Potential relationship between dengue fever and neural tube defects in a northern district of India. Int J Gynaecol Obstet. 1992;39(4): 291-5.

15. Waduge R, Malavige GN, Pradeepan M, Wijeyaratne CN, Fernando S, Seneviratne SL. Dengue infections during pregnancy: a case series from Sri Lanka and review of the literature. J Clin Virol. 2006;37(1):27-33.

16. Morens DM, Halstead SB, Repik PM, Putvatana R, Raybourne N. Simplified plaque reduction neutralization assay for dengue viruses by semimicro methods in BHK-21 cells: comparison of the BHK suspension test with standard plaque reduction neutralization. J Clin Microbiol. 1985;22(2):250-4.

17. Ventura LMO. Sequência de Möbius: estudo comparativo das anomalias e distúrbios funcionais em crianças com ou sem uso de misoprostol durante a gestação [tese]. Minas Gerais: Universidade Federal de Minas Gerais; 2001.

18. Voirin J, Laloum B, Bonté JB, Eckart P, Quedru-Aboane J, Valdazo A. [Moebius syndrome with pharyngo-laryngeal paralysis in a premature infant]. Arch Fr Pediatr. 1991;48(1):35-7. French.

19. Courtens W, Vamos E, Hainaut M, Vergauwen P. Moebius syndrome in an infant exposed in utero to benzodiazepines. J Pediatr. 1992;121(5 Pt 1):833-4.

20. Amaya LG, Walker J, Taylor D. Möbius syndrome: a study and report of 18 cases. Binoc Vis Quarterly. 1990;5(3):119-32.

21. Brasil. Ministério da Saúde. Guia de Vigilância Epidemiológica. Dengue. Brasilia: Ministério da Saúde; 2005. 
22. Cordeiro MT, Schatzmayr HG, Nogueira RMR, Oliveira VF, Melo WT, Carvalho EF. Dengue and dengue hemorrhagic fever in the State of Pernambuco, Brazil, 1995-2006. Rev Soc Bras Med Trop. 2007;40(6):605-11.

23. Barata EA, Costa AI, Chiaravalloti FN, Glasser CM, Barata JM, Natal D. População de Aedes aegypti (1.) em área endêmica de dengue, Sudeste do Brasil. Rev Saúde Pública. 2001;35(3):237-42.
24. Costa AIP, Natal D. Distribuição espacial da dengue e determinantes socioeconômicos em localidade urbana no Sudeste do Brasil. Rev Saúde Pública. 1998; 32(3):232-6.

25. Cordeiro MT. Epidemiologic, clinical and virological observations on dengue in the state of Pernambuco, Brazil. In: 13ํㅡㄹ Encontro Nacional de Virologia; 2002 Águas de Lindóia, Brasil. Anais. Águas de Lindóia; 2002. v.7. p.54.

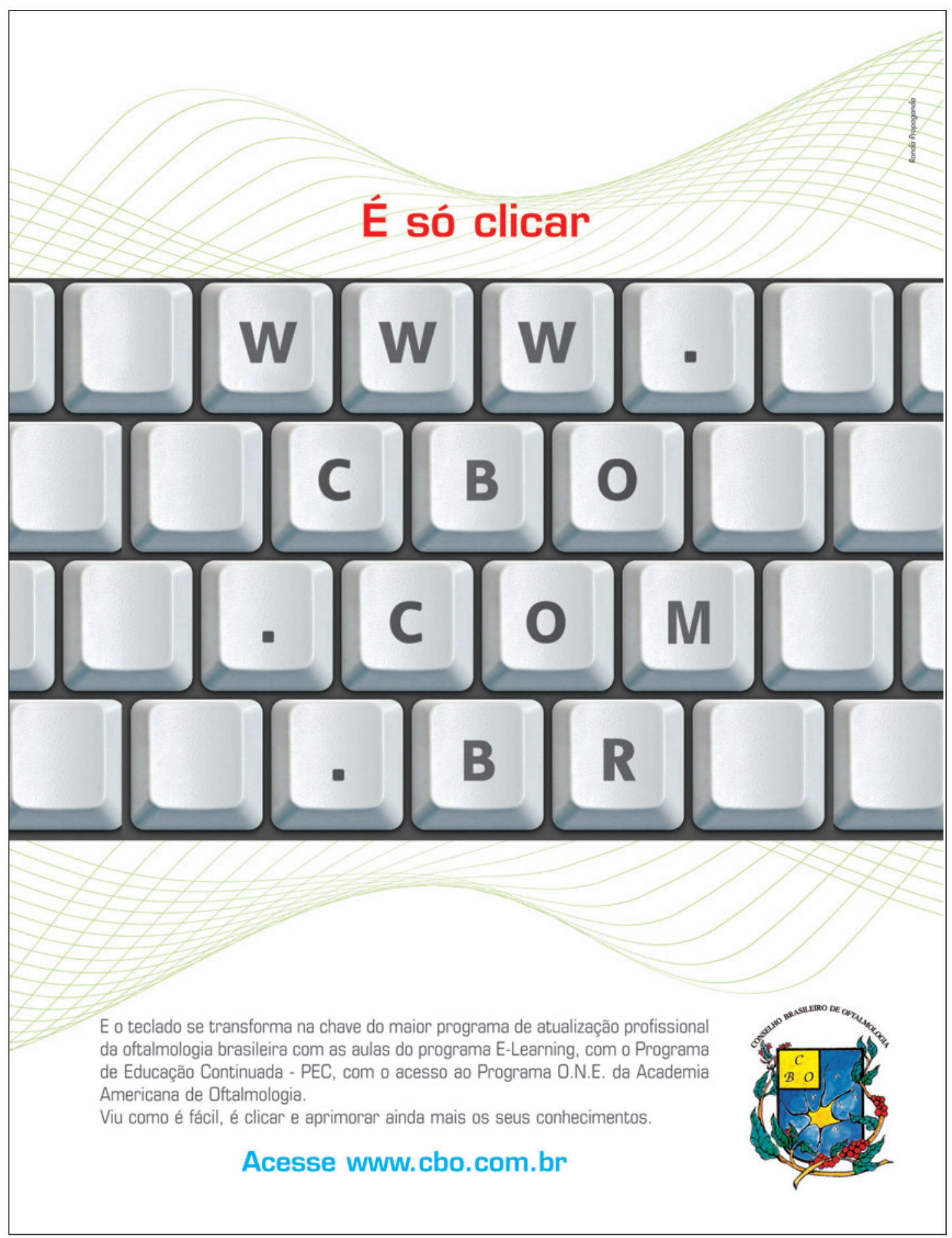

